\title{
Hydrothermal growth of quartz crystals in industry. Present status and evolution
}

\author{
X. BUISSON and R. ARNAUD \\ SICN, 4 rue du Radar, 74008 Annecy, France
}

\begin{abstract}
Review of technical and economic problems encountered in industry.

Improvements that need to be brought, both at process and equipment levels with the help of scientific laboratories. Applications concerning piezoelectric materials.
\end{abstract}

This paper is divided in four parts :

1 - PROCESS" HISTORICAL DEVELOPNENT AND PRESENT STATUS' OUTLINES

2 - MAIN DIFFICULTIES ENCOUNTERED IN HYDROTHERMAL SYNTHESIS

3 - PResent status' Causes

4 - FUTURE AIMS OF HYDROTHERMAL GROWTH

I - HISTORICAL DEVELOPMENT AND PRESENT STATUS 'OUTLINES

I. 1 - HISTORY

Hydrothermal synthesis of quartz was developed after second world war. Industrial development occured chiefly during the 1960 - 1970 period, with a peak between 1968 and 1976, in both USA, JAPAN and EUROPE. 
Presently, production capacity increases chiefly take place in the FAR EAST : KOREA and CHINA.

World capacity can be estimated between 2500 and 3000 tons per year, but these figures can be strongly altered if the grade of the crystals required happened to the changed. The table 1 gives a repartition.

The pressure vessel (autoclave) most used in EUROPE and USA is the "13 inches" vessel (fig. 1) with 350 liters internal volume, which gives some $150 \mathrm{~kg}$ of quartz per cycle. But an evolution concerning vessel's dimensions is to be noted, chiefly in the FAR EAST, where autoclaves with 1000 to 1500 liters internal volume have been installed.

Paraliel to the increase in output, electronic components' manufacturers are looking, since 20 years, for a material with steadily increasing performances for professional applications in the telecommunication field, civilian as well as military.

There is another trend, though the main part of quartz production consists in "Y bar" crystals $i$.e. small crystals $(Z=20$ to $25 \mathrm{~mm}, 3 \mathrm{~mm}$ seed) with a tendency to produce larger crystals ( $z=20$ to $25 \mathrm{~mm}$, 64mm seed) capable of several $Y$ bars per crystal, the "pure $z$ " bars representing 10 to $20 \%$ of this production; but in medium and high quality grades we notice a rising demand for crystals of very large dimensions and upper medium quality, especialiy in the USA, for manufacturing wafers used in surface waves applications.

The production of this last type of crystals will certainly necessitate autoclaves of bigger dimensions, especially in diameter.

\section{I.2 - OUTLINES OF THE PROCESS}

Hydrothermal growth is a process carried out in a closed system that uses a supercritical, or near supercritical aqueous solution that can dissolve raw material in a part of the pressure vessel, and then transport it in another part of the same vessel, where it can crystallize.

The transparency shows such a system, called autoclave. The material to be dissolved is generally called nutrient, in the case of quartz, it is placed in the lower part of the pressure vessel.

The seeds (suitably oriented quartz plates) are placed in the upper part of this vessel.

Both parts are separated by means of a diaphragm with 2 to 10 \% aperture, the percentage of fill determines the operating pressure at a given operating temperature according to KENNEDY'S curves.

The lower part is maintained at a higher temperature than the upper one, in order to maintain steady convection currents transporting the saturated solution from the bottom to the upper part which is colder. The solution becoming thus supersaturated, crystal growth becomes possible.

In the case of quartz, the two solvents commoniy used are soda and sodium carbonate. 
Operating temperature is about $350^{\circ} \mathrm{C}$; for carbonate, pressure is about 900 bars; for soda, it is about 1600 bars.

Cycle duration depends on the dimensions and the quality of the crystals to be produced.

Exemple : for $Y$ bars, $Z=25$ to $30 \mathrm{~mm}$, surtension coefficient $Q=1,8$ $\bar{x} 10^{6}$, cycle duration is about 30 days.

For high quality quartz, $z=40$ to $45 \mathrm{~mm}$, surtension coefficient $Q \geq$ $3,5 \times 10^{6}$, cycle duration is about 120 days.

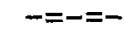

\section{II - MAIN DIFFICULTIES ENCOUNTERED IN HYDROTHERMAL SYNTHESIS}

In this paper, we deal with the difficulties encountered in industry with autoclaves of large dimensions, though such difficulties can be encountered at laboratory scale.

\section{1 - PRESSURE VESSELS}

Chemically inert high pressure vessels, of large dimensions, are needed.

Leak risks must be kept to a minimum and autoclaves must be installed in adapted buildings.

In FRANCE, state regulations are very stringent, they command costly yearly controls : visual, ultrasonic and magnetoscopic. This necessitates an investment which is big when compared to the yearly income generated by an autoclave.

\section{2 - GROWTH SPEED}

It is difficult to evaluate accurately the growth speed; in the case of very long duration growth cycles, a minor error on growth speed estimation ( 2 \& for example) can lead to several millimeters in dimensions variations by the end of the cycle, and rejection of the crystals.

Profitability commands, in fact, to determine the maximum number of crystals seeds to be put into an autoclave.

\section{3 - GROWTH MONITORING}

During growth, no visual inspection is possible and the present control means, i.e. temperature measurements, are of limited use and do not permit to follow the growth with sufficient accuracy.

More precision in monitoring would be particularly welcome during the starting phase of the growth cycle; the correct proceeding of the growth during the first two days of the cycle has a tremendous influence on the quality of crystals, and the growth initiation on the seed is of prime importance. 
The monitoring of an autoclave, either manual or computer-assisted, is more often empirical than dictated by a precise knowledge of physicochemical processes.

Each manufacturer follows his own rules, which result more often of experience than of a scientifical approach.

\section{4 - CONSEQUENCES}

All these difficulties often result in a lack of reproducibility -from an industrial point of view- especially in the case of very high quality and/or large size crystals.

This is obvious1y far less sensitive on the laboratory and on the pilot scale, because the thermal conditions are easier to control -at least for quartz-.

\section{III - REASONS LEADING TO THE PRESENT STATUS}

A study by prof. MROCZKOWSKY, of YALE University, shows (illustrated in fig. 2), the number of published papers concerning hydrothermal growth between 1962 and 1985. It appears that a great part of applied research works were not published. But we see that the interest about hydrothermal growth rises strongly between 1962 and 1972, and then collapses, as shows the decrease of research's volume.

Several elements can be considered :

\section{III.1 - QUARTZ SYNDRONE}

The first element is what Prof. HROCzKOWSKI calls "quartz syndrome".

Quartz" success leads to the development of hydrothermal growth, but the needs for a cheap material in the largest number of applications: clocks, microprocessors..., result in beeing contented with a "medium" quality product, and the low profitability of this kind of product results in the impossibility of financing long and costly studies.

\section{III.2 - USERS ARE MORE APPLICATIONS-INTERESTED THAN MATERIAL- INTERESTED}

For many years, quartz users have been more interested in the applications of quartz, i.e. in the improvements to the brought to their final products, than to the potential improvements that could be brought by a rise in the performances of the base-matexial used, that is to day, by intrinsic quality of quartz.

Some users became conscious of this possibility since a few years, but they remain a minority.

Outside of quartz, no material coming from hydrothermal synthesis has sizable industrial use, even if $\mathrm{AI} \mathrm{PO}_{4}$, $\mathrm{Ga} \mathrm{PO}_{4}$, or microcrystallites show interesting promises, industry does not seem ready to make an important $R \& D$ effort concerning these products. 
It is thus difficult to get any financial support to develop a better knowledge in hydrothermal growth, this matter is highly intricate and necessitates an important effort during a long time. Private industry cannot deal alone with the costs of such a program, even in the USA, research programs are government-sponsored, especially in defence field.

\section{III.3 - SHORTCOMINGS IN THEORETICAL KNOWLEDGE}

Hydrothermal growth is used as an industrial process since 35 years and more, but, though many improvements have been brought to it, it is still more a craft than a truly reproducible, industrial, process.

What are the conditions for a successfull hydrothermal growth operation ?

Knowledge about parameters commanding the process must be improved $i . e$. :

- phase relationships,

- nutrient's solubility,

- state equations (thermodynamics),

- kinetics of reaction (").

- impurities repartition,

- crystal defects" characterization.

Presently, no important theoretical research on these topics is taking place, neither in industry, nor in university laboratories.

\section{III.4 - INSUFFICIENT TECHNOLOGICAL STUDIES}

The design of quartz synthesis autoclaves do not show any significant evolution during the last thirty years, especially about the vessel's material, but solvent's chemical reactivity towards the vessel's walls can cause defects, i.e. acmite inclusions in the crystals.

And in the case of crystals like $\mathrm{AlPO}_{4}$ and $\mathrm{GaPO}_{4}$, corrosion problems are far more acute.

Lining the vessel with noble metal (silver, platinum...) sleeves is used on laboratory scale, but is not of sufficiently easy use for industry, and far too expensive.

Some studies led by corrosion specialists would be welcome.

$$
-=-=-
$$

\section{IV - FUTURE AIMS OF HYDROTHERMAL GROFTH}

The general objective is, of course, to get crystals with no dislocations and very low impurities content.

These crystals must be grown in industrial size autoclaves in order to maintain cost at a reasonable level, and the growth conditions must be reproducible. 
It is of no use, to the industrial user, to produce "super crystals" on a laboratory or pilot-plant scale.

Crystals quality is necessary in order to meet the rise in performances of the piezo-electric devices that the costumers expect, and to make the best out of new "machining" techniques (chemical machining).

Five main ways must be explored :

- improvements on theoretical knowledge,

- improvements on quality of solvents, nutrients, seeds,

- improvements on autoclaves' technology : material, dimensional ratio diameter/length, crystallization zone/dissolution zone...

- basic questionning of the validity of presently used growth parameters (pressure, temperature).

- better understanding of complementary treatments such as sweeping.

Preliminary studies led in some laboratories show promising results, important improvements on the quartz material are still possible.

These studies will, besides, have important consequential effects on hydrothermal growth in general, and facilitate the development of other materials production. 


\begin{tabular}{|c|c|c|c|}
\hline \multicolumn{2}{|r|}{ PRODUCIION } & \multicolumn{2}{|c|}{$\begin{array}{l}\text { ESTIMATE } \\
1993\end{array}$} \\
\hline & $\mathbf{U} \mathbf{S} A$ & 600 & TONS \\
\hline & JAPAN & 1600 & TONS \\
\hline & CHINA & 350 & TONS \\
\hline & KOREA & 50 & TONS \\
\hline & OTHER COUNTRIES & 400 & TONS \\
\hline
\end{tabular}

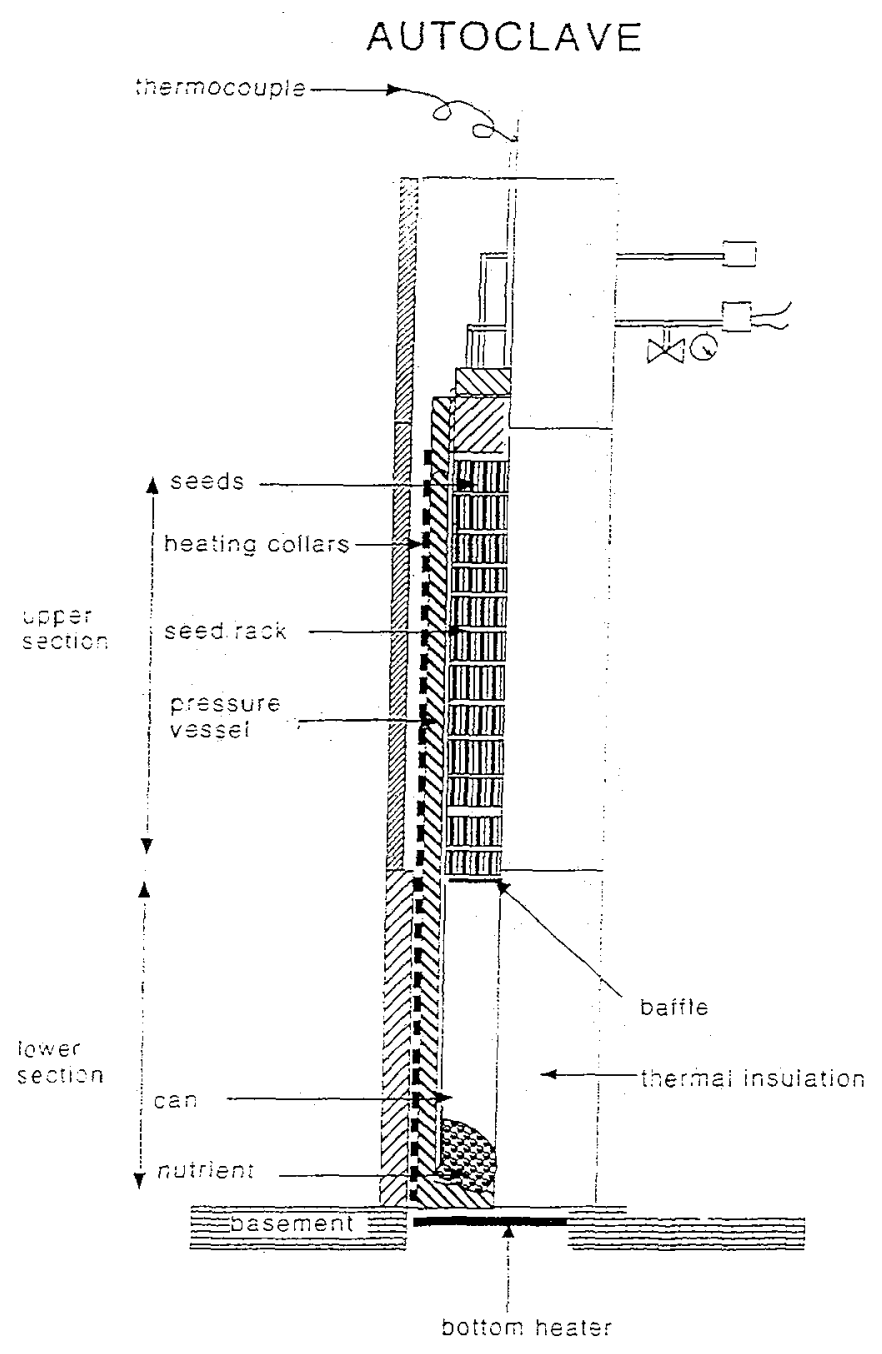



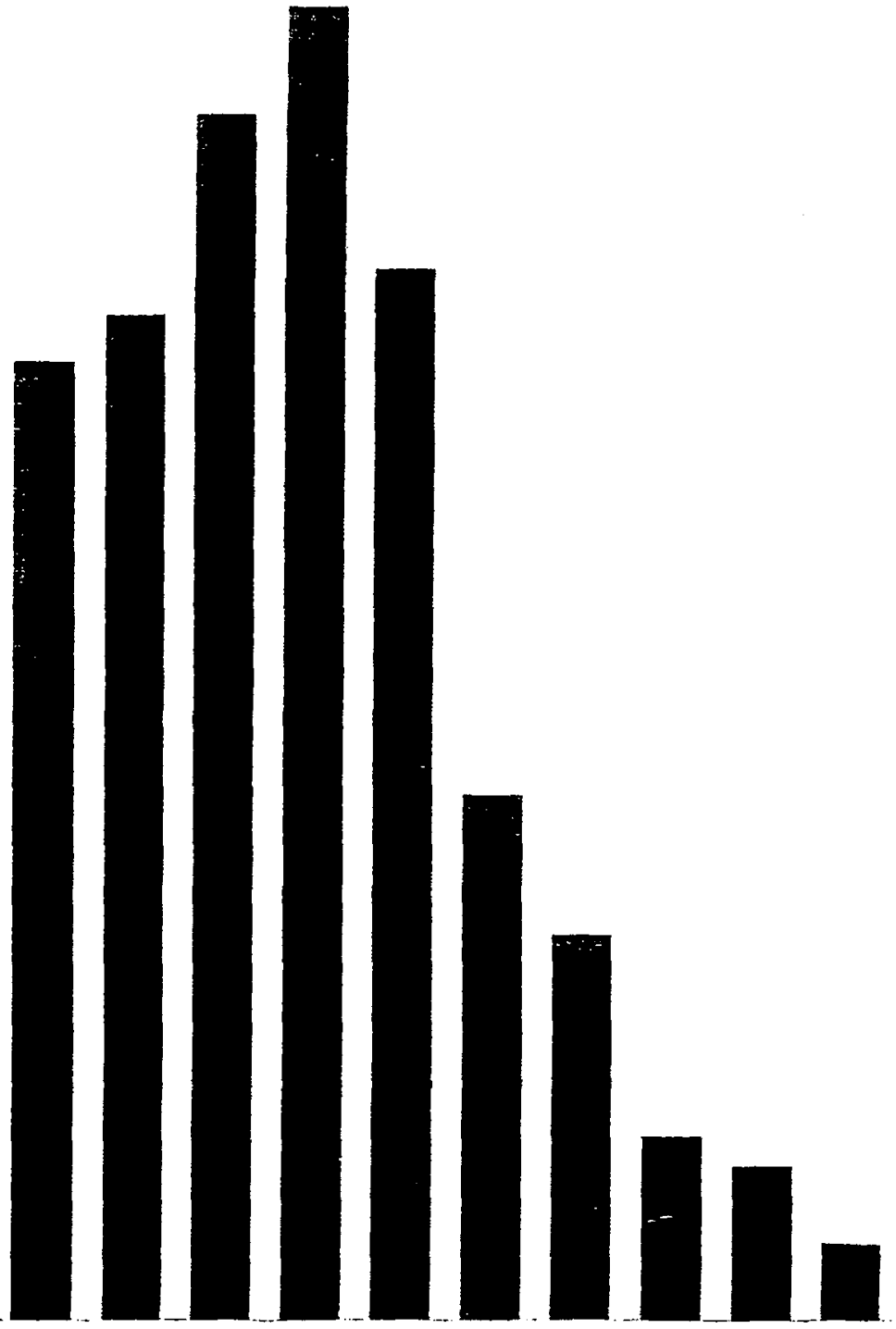

$\cdot 962$

1972

1974

1976

1978

1980

1982

1984

fig. 2 